\title{
Guideline for the management of pre-, intra-, and postpartum care of women with a spinal cord injury
}

\author{
Sue Bertschy ${ }^{1} \cdot$ Markus Schmidt $^{2} \cdot$ Kai Fiebag $^{3} \cdot$ Ute Lange $^{4} \cdot$ Simone Kues $^{5} \cdot$ Ines Kurze $^{6}$
}

Received: 4 September 2019 / Revised: 20 November 2019 / Accepted: 21 November 2019 / Published online: 6 December 2019

(c) The Author(s), under exclusive licence to International Spinal Cord Society 2019

\begin{abstract}
The German Association of the Scientific Medical Societies guideline for pregnancy, childbirth, and puerperium in women with a spinal cord injury (SCI) addresses a range of topics from the desire to have a child to different stages of pregnancy and birth. Given that a generally accessible and evidence-based presentation of this complex issue does not yet exist, this new guideline contributes to the standardization of gynecological, obstetric, and maternal care of women with SCI. This guideline aims to provide practice-oriented support for the care and counseling of women in the pre-, intra-, and postpartum periods; to close identified gaps in medical care; foster collaboration among clinicians of relevant disciplines; and inspire research.
\end{abstract}

\section{Introduction}

Spinal cord injury (SCI) in women requires them to interact with multiple service providers, monitor their health status, and make well-informed care decisions, including those associated with maternal care, pregnancy, and childbirth [1]. SCI does not necessarily diminish a woman's desire or ability to give birth [2,3]. Although rare, pregnancies among women with SCI are increasing and usually have favorable outcomes [2-4]. However, various factors should

The full reference list is available as supplementary file (Appendix 1).

Supplementary information The online version of this article (https:// doi.org/10.1038/s41393-019-0389-7) contains supplementary material, which is available to authorized users.

Sue Bertschy

sue.bertschy@paraplegie.ch

1 Swiss Paraplegic Research (SPF), Nottwil, Switzerland

2 Sana Clinics Duisburg, Duisburg, Germany

3 Department of Neuro-urology, BG Clinic Hamburg, Hamburg, Germany

4 Department of Applied Heath Sciences, University of Applied Sciences, Bochum, Germany

5 Department of Psychology, BG Clinic Hamburg, Hamburg, Germany

6 Department for Paraplegia and Neuro-urology, Centre of Spinal Cord Injuries and Diseases, Bad Berka, Germany be considered during pregnancy and childbirth. Secondary health conditions, such as urological complications, thromboembolism, and autonomic dysfunction, have been reported and should be monitored closely [4-6].

Despite the ratification of the United Nations Convention on the Rights of Persons with Disabilities to ensure equal, uninterrupted, timely, and comprehensive healthcare to all, pregnant women with SCI often encounter obstacles when accessing appropriate services [7]. These include system fragmentation and a lack of coordination among providers, physical accessibility, SCI-specific knowledge, and quality information to support self-management and decision making $[4,8,9]$.

There are few evidence-based recommendations pertaining to optimal care for pregnant women with SCI. The German Association of the Scientific Medical Societies published Guideline 179-002 [10] to establish interdisciplinary standards in Germany and in other European countries for spinal cord medicine, as well as neuro-urological, gynecological, and obstetric discussed aspects that influence the usage and quality of care. This article summarizes important parts of this guideline to assist healthcare providers in their daily routine.

\section{Aim of the guideline}

The committee addressed the full spectrum of current clinical dilemmas in the counseling and treatment of women with SCI pre-, intra-, and postpartum: (i) characteristics of 
Table 1 Overview of possible health conditions during pregnancy and their management.

\begin{tabular}{|c|c|c|c|c|}
\hline & 1st trimester & 2nd trimester & 3rd trimester & Management \\
\hline Vegetative & $\begin{array}{l}\text { Autonomic } \\
\text { dysreflexia }\end{array}$ & $\begin{array}{l}\text { Autonomic } \\
\text { dysreflexia }\end{array}$ & Autonomic dysreflexia & $\begin{array}{l}\text { Elevate upper body } \\
\text { Eliminate trigger stimulus } \\
\text { Antihypertensives } \rightarrow \text { PDA peripartum }\end{array}$ \\
\hline Bladder & $\begin{array}{l}\text { Urinary tract } \\
\text { infection (UTI) } \\
\text { Urinary incontinence }\end{array}$ & $\begin{array}{l}\text { UTI } \\
\text { Urinary } \\
\text { incontinence } \\
\text { Pyelonephritis } \\
\text { Urinary calculus }\end{array}$ & $\begin{array}{l}\text { UTI } \\
\text { Urinary incontinence } \\
\text { Pyelonephritis } \\
\text { Urinary calculus }\end{array}$ & $\begin{array}{l}\text { UTI-prophylaxis after pyelonephritis } \\
\uparrow \text { Catheterization frequency } \\
\text { Consider an indwelling catheter for a } \\
\text { short period }\end{array}$ \\
\hline Bowel & Obstipation & Obstipation & $\begin{array}{l}\text { Obstipation } \\
\text { Bowel management influenced } \\
\text { by pressure on bowel } \\
\text { Positioning for defecation }\end{array}$ & $\begin{array}{l}\text { Adjust nutrition and drinking habits } \\
\text { Adapt bowel management to medication } \\
\text { and stool consistency } \\
\text { Consider additional assistance }\end{array}$ \\
\hline Skin & & $\begin{array}{l}\uparrow \text { Risk of } \\
\text { pressure ulcers }\end{array}$ & $\uparrow$ Risk of pressure ulcers & $\begin{array}{l}\uparrow \text { Pressure relief } \\
\uparrow \text { Frequency of skin checks } \\
\downarrow \text { Transfers } \\
\text { Consider adaptation of aids (cushion, } \\
\text { mattress, shower bench or chair) }\end{array}$ \\
\hline Weight & & $\uparrow$ Weight & $\uparrow$ Weight & Healthy nourishment \\
\hline Mobility & & & $\begin{array}{l}\text { Reduced mobility and altered } \\
\text { body mechanics may need to be } \\
\text { adjusted } \\
\uparrow \text { Fatigue } \\
\uparrow \text { Dependency in daily activities } \\
\text { and dressing }\end{array}$ & $\begin{array}{l}\text { Consider changes in daily wheelchair } \\
\text { (positioning of axles, anti-tip bars) } \\
\text { Consider hiring an electric wheelchair for a } \\
\text { short period } \\
\text { Practice situations before baby belly grows } \\
\text { (Put a ball under t-shirt) } \\
\text { Consider additional time in daily life }\end{array}$ \\
\hline Spasticity & & & $\uparrow$ Spasticity & $\begin{array}{l}\text { Consider physiotherapy } \\
\text { Avoid situations that cause spasms }\end{array}$ \\
\hline $\begin{array}{l}\text { Respiratory } \\
\text { function }\end{array}$ & & & $\begin{array}{l}\text { Limited breathing and vital } \\
\text { capacity } \\
\text { Decreased effective coughing } \\
\text { capacity }\end{array}$ & $\begin{array}{l}\text { Breathing physiotherapy } \\
\text { Breath support by overpressure inhalation } \\
\text { or CPAP application } \\
\text { Ingestion of secretolytics }\end{array}$ \\
\hline
\end{tabular}

and frequent complications, (ii) preconceptual considerations, (iii) planning for birth and labor, and (iv) postnatal care.

\section{Composition of guideline committee}

The guideline committee included multidisciplinary health experts convened by the Society of Gynecological and Obstetric Medicine of Germany and German Medical Society of Paraplegia. These healthcare experts represented the fields of obstetrics and gynecology, midwifery, spinal cord medicine, neuro-urology, anesthesiology, psychology, respiratory therapy, peer counseling, and health sciences.

\section{Characteristics and frequent complications}

\section{Characteristics of women who give birth after SCI}

In Germany and other German-speaking countries, basic epidemiological information on pregnancy rates in women with SCI is unavailable. According to international studies, an estimated 14-18\% of women with SCI have children after the event, and with medical advances, this number is increasing $[5,9,11]$. Apart from the time of injury, marital status, etiology, education, and work status can influence the decision to bear children after SCI $[6,12]$. Mothers with SCI tend to live in stable partnerships, are well-educated, have high household incomes, and are employed [4, 9]. On average, women with SCI wait 5-15 years after the injury to become pregnant, and they tend to give birth to their first child an average of 2-3 years later than nondisabled women $[5,12]$.

\section{Management of frequent complications during pregnancy in $\mathrm{SCl}$ women}

Complications during pregnancy with the highest relative risk of occurrence are urinary tract infections/pyelonephritis, venous thrombosis/pulmonary embolism, preterm rupture of membranes, and preterm/obstructed labor [5, 13]. Tetraplegic women may be especially prone to severe complications of autonomic dysreflexia and respiratory 
distress [6] (Table 1). Antenatal hospitalizations, and preterm labor are common in pregnant SCI women [3, 5]. Although the infants of SCI women are more likely to be born preterm and small for gestational age, they do not experience greater risk of long-term adverse outcomes, such as rehospitalization and death [13, 14].

\section{Bladder}

Urological problems, especially UTIs, urinary incontinence, and frequent bladder emptying, are the most common complications during pregnancy with SCI [3, 5, 15]. Antibiotic therapies may be needed for UTIs caused by frequent catheterization, hydronephrosis, and neurogenic bladder dysfunction [4, 15]. Chronic UTIs, pyelonephritis, and septicemia increase the risk of early birth $[4,15]$. Therefore, urine specimens should be collected every 4 weeks, including urine culture through catheterization. Clinical signs and symptoms of UTI experienced by patients with SCI may differ from the classic genitourinary symptoms experienced by patients with normal sensation. Since SCI frequently results in sensory loss, urinary retention might remain asymptomatic. In order to discover urinary drainage failures at an early stage, ultrasound examinations of the urinary tract should be performed regularly. In addition, blood tests and antibiotics should be administered if necessary.

\section{Bowel}

Pregnancy is associated with a higher rate of constipation [6]. Therefore, it is important to adopt a fiber-rich diet and consume adequate amounts of liquids. The use of lactulose as a stool softener can be helpful, but it can increase the likelihood of meteorism. Therefore, alternative methods such as colon massage are recommended [16].

\section{Skin}

Pregnancy-related weight gain, skin dryness, and pressure point changes over the pelvis are associated with a latent risk of harm to the skin and may cause pressure injuries [14].
Regular relief, repositioning within the wheelchair, and skin control may be necessary. In addition, a larger wheelchair and modification of the seat cushion and mattress (i.e., antidecubitus) may be required. The use of nonsensitizing, pH-balanced, fragrance-free, and alcohol-free emollient moisturizer is recommended for dry skin [17].

\section{Weight}

Weight control should be performed every 4 weeks, increasing to every 2 weeks in the last 2 months of pregnancy. If a lifter is available for daily use, it can be extended with the weighing function to independently document weight. Postpartum weight loss in women with SCI is a difficult process owing to limited mobility and low energy consumption. A healthy diet should be considered early on [18]. Weight gain can be caused by increased edema.

\section{Respiration}

Respiratory complications are dependent on the SCI level and degree of motor impairment [19]. Because tetraplegia and high paraplegia $\left(\mathrm{T}_{4}\right)$ increase the risk of respiratory insufficiency in the second and third trimesters, physiotherapy-supported respiratory therapy is recommended [6]. Respiratory therapy equipment, mechanical ablation aids, and nocturnal mask ventilation may be needed during pregnancy [20].

\section{Autonomous dysreflexia}

Autonomous dysreflexia (AD) generally occurs in patients with SCI levels of $\mathrm{T}_{6}$ and higher and in $\mathrm{AD}$-provoking situations [21]. Painful stimuli in the paralyzed area (labor, manipulation before or during delivery, vaginal or rectal examination, and cesarean section) can trigger AD without the woman feeling pain [22]. Other AD-triggering factors include urinary retention upon stimulation with adrenergic afferents, catheterization, provocation by urodynamics or cystoscopy, sexual stimulation, bowel distension, provocation by vaginal examination (speculum adjustment), and

Table 2 Differential diagnoses of autonomous dysreflexia vs preeclampsia.

\begin{tabular}{lll}
\hline & Autonomous dysreflexia & Preeclampsia \\
\hline Lesion level & Often above lesion level T6 & Independent of lesion level \\
Blood pressure & Attacking and extremely intensive & Slowly increasing \\
Heart rate & Mostly bradycardic, early phase of tachycardia & Mostly normofrequent \\
Proteinuria & No & Yes ( $>300 \mathrm{mg} / 24 \mathrm{~h}$ ) \\
Clinical observation & "Flushing," sweating, goose pimples, pounding & $\begin{array}{l}\text { Edema, continuous headache, flickering vision, pain in upper } \\
\text { abdomen, and increased reflexes }\end{array}$ \\
Serological & headache, and increased reflexes & $\begin{array}{l}\text { Possible, for example, with concurrent HELLP syndrome (uric } \\
\text { acid } \uparrow, \text { transaminase } \uparrow, \text { thrombocyte } \downarrow \text {, and haptoglobin } \downarrow)\end{array}$ \\
\hline
\end{tabular}


rectal manipulation (defecation, examination) [21, 23]. Close monitoring is highly recommended, and management involves normalizing the heart rate and blood pressure and clearing the symptoms of $\mathrm{AD}$. AD must be differentiated from preeclampsia (Table 2); hemolysis, elevated liver enzymes, and low platelets syndrome; and sinus vein thrombosis. For most women with SCI, distinguishing between preeclampsia and $\mathrm{AD}$ is only possible with clinical and laboratory testing. If sinus vein thrombosis is suspected, magnetic resonance imaging of the skull is required.

\section{Thrombosis}

In SCI and pregnancy in general, there is an increased risk of thrombosis owing to hormonal changes and altered pressure in the abdominal area with decreased blood flow, especially to the pelvis and leg veins [24, 25]. Venous thromboembolism can be prevented through careful assessment of existing and new risk factors. Due to increasing immobility in the last trimester of pregnancy, thrombosis prophylaxis is recommended from the 28th week of pregnancy to 6 weeks postpartum. In addition to regular leg elevation, cold showering, increased passive or active movement, and support stockings, drug therapy using low-molecular-weight heparins is recommended.

\section{Preconceptual considerations}

Preconceptual counseling is important for women with SCI who are considering having a child. Such counseling aims to improve the health of women before pregnancy and thus achieve primary prevention in both the medical and social fields. In the absence of a specialized SCI center, preconceptual planning should be coordinated by a gynecologist/obstetrician in close collaboration with the treating rehabilitation physician or neuro-urologist. The following checklist provides an overview of the important aspects to be considered preconceptually and during pregnancy:

\section{Preconceptual checklist:}

1. Neurological, psychological, and orthopedic stability

2. Review and pause medication if necessary

3. Substitute folic acid

4. Check urinary and bowel management

5. Check for implants

\section{Preconceptual medical assessment}

Neurological, psychological, and orthopedic stability should be evaluated and the existing medication reviewed, amended, or (if necessary) paused. Changes to existing medication should be made in close collaboration with the treating physician. Focus should be on the neurological, neuro-urological, and orthopedic stability due to the physical changes expected over the course of a planned pregnancy. Additional counseling is needed for women with congenital spinal paralysis (spina bifida), which can be found in the extended guideline (Section 2.1.2.1) [10]. Furthermore, the supply of assistive devices should be evaluated, medical implants discussed, folic acid initiated, and contacts with peer groups arranged [26].

\section{Medication}

Women with SCI are usually adjusted to multiple medications owing to the associated symptoms. To avoid serious side effects to the unborn child, these medications should be reviewed before pregnancy.

\section{Antibiotic medication}

Antibiotic therapies for UTIs are often necessary during pregnancy in women with SCI [15]. Antibiotic treatment should be initiated when necessary, even in the case of asymptomatic bacteriuria. Due to the increased risk of multidrug-resistant germs, a urine culture should always be collected and susceptibility testing initiated before starting antibiotic treatment. A longer-lasting course (7-10 days) and high dosage should be administered. The role of continuous low dose antibiotic prophylaxis in the case of pregnancy without relevant comorbidities is still unclear; however, after pyelonephritis, a long-term antibiotic prevention for the entire duration of pregnancy is recommended [27]. After treating pyelonephritis, a urine culture should be collected to verify the success of the therapy. The decision to initiate an antibiotic therapy must always be strict and tailored to the individual. Betalactam antibiotics should be the first choice and nitrofurantoin the second, but the latter should not be used in the third trimester [28].

\section{Anticholinergic and antimuscarinic medication}

No reliable data are available for prescribing anticholinergic drugs to pregnant women with SCI. These drugs should be avoided to the extent possible in the first trimester. Although there are no systematic data on the use of oxybutynin in pregnancy, neither are there data about the embryotoxic risks of oxybutynin. A French study found no differences in pregnancy outcomes in 53 pregnancies with oxybutynin exposure (35 in the first trimester) compared with 70 control pregnancies [29]. There is no evidence related to the use trospium chloride or propiverine in pregnant women, but animal studies have not indicated 
reproductive toxicity. If these drugs are prescribed, attention should be paid to fetal side effects (e.g., tachycardia).

\section{Botulinum toxin}

Intramuscular botulinum toxin (BoNT)-A injections into the detrusor vesicae before pregnancy may be an option to compensate for the lack of bladder-relaxing effect of anticholinergic or antimuscarinic drugs. A 200-MU BoNTA injection into the detrusor is an officially approved therapy for subcervical SCI beyond pregnancy. In cervical SCI, there is still an off-label use scenario. The effect of BoNT-A on the bladder persists for 6-9 months; therefore, overactivity of the detrusor can be suppressed adequately, at least for part of the pregnancy [30,31]. The data on general BoNT-A exposure during pregnancy is limited. Approximately 20 known cases, most involving treatment of cervical dystonia, indicated no specific risks. In case reports of pregnant women suffering from botulism, the child's health was unaffected, leading to the assumption that BoNT does not pass through the placental barrier [30].

\section{Anti-spasticity medication}

Medications to reduce spinal spasticity are among the most commonly used drugs in spinal cord medicine [32]. The classic representatives of orally administered and approved anti-spastic drugs in Germany are baclofen and tizanidine, benzodiazepines (e.g., diazepam), and dantrolene [33]. Because of their serious side effects, these substances are not recommended during pregnancy and should only be used in exceptional situations. Diazepam may be used in the short-term for select individuals but increases the risk of floppy infant syndrome. For tizanidine, there is no sufficient experience with human use in pregnancy. However, animal fetotoxicity has been demonstrated [28]. Proceed stepwise when discontinuing anti-spasticity drugs.

\section{Pain medication}

For the treatment of neuropathic pain, pregabalin and gabapentin are primarily used [34]. There are insufficient data on the use of these agents in pregnant women. However, the use of pregabalin was assessed critically in a study [35] in 2016, which reported an increased risk of severe malformations. Pregabalin use should be considered only if the potential benefit to the mother is significantly higher than the potential risk to the fetus. During pregnancy, paracetamol is considered the first-line analgesic and antipyretic. To prevent the risk of hepatotoxicity, the maximum daily dose should not exceed $4 \mathrm{~g}$, and long-term therapy should be subjected to a strict indication. Metamizole should not be used during pregnancy [36]. Among NSAIDs, ibuprofen and diclofenac may be used in the first two trimesters. In the last trimester, however, they are contraindicated because of the possibility of premature closure of the ductus arteriosus. Fetal renal failure and oligohydramnios are commonly reported complications resulting from the use of all NSAIDs in the last trimester. If acetaminophen or NSAIDs are inadequate for pain management, WHO-II oral opioids such as tramadol or tilidin may be prescribed. In general, opioids are not associated with increased risk of malformation. As with peripartum administration, opioids can lead to neonatal apnea requiring therapy or can affect heart rate variability with the risk of fetal hypoxia. In cases of chronic use, postpartum withdrawal symptoms may occur in the mother and child [36].

\section{Laxative medication}

According to technical information [28], there is a strict indication for sodium picosulfate during pregnancy. However, there are no studies on its use during pregnancy. Owing to its low absorption and long market experience, no increase in the risk of malformation is assumed; thus, its short-term use may be considered for persistent constipation [28]. Herbal laxatives such as anthraquinone derivatives (senna, rhubarb root, alder buckthorn, and aloe), paraffin, and castor oil should not be used [28]. Alternatively, dietary measures such as increased fiber intake (wheat bran, linseed, and psyllium) may be recommended in combination with sufficient liquid intake. Colon massage to stimulate peristalsis may be helpful as well. In case of ongoing constipation, lactulose or macrogol can be used as alternatives to plasticizers [28] (Caution: Meteorism). In addition to digital stimulation, bisacodyl or glycerol can be used as a rectal laxative in the short-term. Carbon dioxidereleasing suppositories are harmless [28]. Glauber's salt and rectal administration of mannitol or sorbitol are also acceptable.

\section{Medication with autonomous dysreflexia}

Therapy for AD should eliminate the cause if possible by stopping the manipulation or emptying the bladder or bowel [21]. Antihypertensive medications include nifedipine oral $5 \mathrm{mg}$ initially (up to $10 \mathrm{mg}$ ), repeating after $20 \mathrm{~min}$ if necessary; intravenous urapidil $6.25 \mathrm{mg}$ slowly, then increasing 3-24 $\mathrm{mg} / \mathrm{h}$ with a perfusor; or $5 \mathrm{mg}$ intravenous dihydralazine slowly, then increasing $2-20 \mathrm{mg} / \mathrm{h}$ with a perfusor. An acute reduction in blood pressure should be initiated using cardiotocography as soon as the survival of the unborn child is guaranteed [37]. If maternal vitality is endangered, intravenous urapidil should be escalated slowly to $10-50 \mathrm{mg}$, or fast-acting nitro preparations (e.g., up to 
three strokes of nitrospray or sublingual) may be administered [21].

\section{Medication during birth}

Well-known obstetrical medications and common peripartum drugs can also be administrated to women with SCI. These include tocolytics, such as fenoterol, atosiban, and magnesium, and prostaglandins for labor induction. Medication with vasoconstrictive effects, such as the ergotamine derivative Methergine, should not be administered in cases of atonic uterine bleeding [28].

\section{Medication during lactation}

Breastfeeding has positive aspects for mother and child. An individual decision, which weighs the wishes of the mother with potential contraindications for some medication during lactation, should be made $[28,36]$. Table 3 gives examples for medication during lactation.

\section{Implants}

In women with SCI, implants can be used for sacral neuromodulation and sacral anterior root stimulation, as well as with artificial bladder sphincters, drug pumps, and ventriculoperitoneal or ventriculoatrial shunts [38-40]. Studies on the use of these implants during pregnancy are rare. Habitual voiding technique should be maintained during pregnancy in SCI women with sacral neuromodulation. If sacral anterior root stimulation is performed for voiding the urinary bladder, it can be continued during pregnancy. In the absence of meaningful literature data on potential damage to the urethra, bladder, and sphincter, a urethral sphincter replacement might be an indication for a primary cesarean section. Few published cases describing the course of pregnancy with an implanted intrathecal baclofen pump are available, but overall, the rate of complication is low. The application of intrathecal baclofen does not seemingly endanger the child.

\section{Fertility and reproductive techniques}

With the exception of a relatively short period of amenorrhea after acute SCI, endocrine function returns to normal, and thus, fertility is not limited regarding the endocrine system [41]. Intrauterine insemination and artificial insemination have successfully been performed in women with SCI. There is no increased risk of thrombosis with low dose hormonal stimulation which is frequently used for intrauterine insemination or modified natural cycle IVF. However, high dose stimulation as used for conventional IVF increases the risk of thrombosis. There is a risk of $\mathrm{AD}$ in case of pelvic manipulation, especially in follicle aspiration for IVF. Anesthesia might be necessary depending on the disposition of the individual to $\mathrm{AD}$ and the invasiveness or potential pain stimulus of the intervention. In any case, continuous blood pressure monitoring is recommended if the risk of $\mathrm{AD}$ is given such in follicle aspiration. Multiple pregnancies put women with SCI at an increased risk and should be avoided by intrauterine insemination only being performed in monofollicular cycles and by transferring only one embryo in IVF. Overall, a careful risk assessment should be performed before the application of reproductive medical procedures, and appropriate measures should be discussed with the individual.

\section{Planning for birth and labor}

This should always proceed in accordance with the maternity care team, and an early prenatal presentation in an anesthesiologic consultation is recommended [6]. Anesthesiologic difficulties may occur, especially in the case of AD $[42,43]$, altered respiratory physiology, impaired thermoregulation, and altered anatomical conditions (e.g., spina bifida patients or surgically stabilized spine). The general aspects of anesthesiologic preoperative evaluation include premedication, AD episodes, tendency to hypotension, recurrent pneumonia, thromboembolic complications,
Table 3 Medication during lactation.

\begin{tabular}{|c|c|c|}
\hline & Medication & Lactation \\
\hline Antispasmodics & $\begin{array}{l}\text { Lioresal } \\
\text { Diazepam }\end{array}$ & $\begin{array}{l}\text { No use } \\
\text { Relatively contraindicated, short-term use }\end{array}$ \\
\hline Anticholinergics & $\begin{array}{l}\text { Trospiumchlorid, Propiverin, } \\
\text { Oxybutynin } \\
\text { Botulinum toxin }\end{array}$ & $\begin{array}{l}\text { Use under strict indication } \\
\text { Should not be used }\end{array}$ \\
\hline Pain medication & $\begin{array}{l}\text { Paracetamol } \\
\text { Ibuprofen } \\
\text { Metamizol }\end{array}$ & $\begin{array}{l}\text { First drug of choice } \\
\text { Medium of first choice } \\
\text { Avoid as much as possible, administer single } \\
\text { dose if necessary }\end{array}$ \\
\hline Antiepileptics & $\begin{array}{l}\text { Gabapentin } \\
\text { Pregabalin }\end{array}$ & $\begin{array}{l}\text { Monotherapy possible } \\
\text { Low-dose monotherapy possible }\end{array}$ \\
\hline
\end{tabular}


intracranial pressure (in shunt wearers), allergies or anaphylaxis (e.g., latex in spina bifida), anemia, decubitus, UTIs, neurological status, and previous operations, especially in the spine area. Additional diagnostics include current laboratory values for blood count, coagulation, electrolytes, renal retention, C-reactive protein, liver, blood gas analysis, and lung function.

The lack of contractions, especially in women with injuries above $\mathrm{T}_{10}$, may led to unplanned home births, unattended hospital births, or hospitalization during advanced birthing. We recommend observing for signs of labor (e.g., increased spasticity, shortness of breath) at about 28 weeks of pregnancy [44]. Pregnant women with SCI should be educated in uterine palpation techniques to detect contractions at home [6].

\section{Epidural catheter}

Lesion levels above $T_{6}$ require early placement of an epidural catheter at neurological segment $\mathrm{T}_{10}$ before the onset of labor and continuous patient-controlled epidural analgesia through a pumping system, owing to the risk of autonomic labor dysreflexia [42]. There are very few contraindications for the implantation of epidural catheters in SCI women [45]. Knowledge of neurological status is always necessary. Women should be made aware of the difficulties of puncture; misplacement; duraperforation; and incomplete block or failure owing to changing anatomical conditions, previous operations and implants, and spinal spasm. Patientcontrolled epidural analgesia should be continued until $48 \mathrm{~h}$ postpartum in women with known $\mathrm{AD}$ tendencies [46]. If there is a risk of $\mathrm{AD}$, prolonged delivery room monitoring with close-meshed vital sign control or extended continuous monitoring under epidural catheter or patient-controlled epidural analgesia should be performed for $48 \mathrm{~h}$.

\section{Dilation phase}

The mother and child should be monitored using the same standards as for women without SCI. Depending on the circumstances, early admission to the maternity ward can be considered [6]. During birth, one-to-one midwifery care may be favorable. In women with lesions above $\mathrm{T}_{6}$, owing to the possibility of $\mathrm{AD}$, close-circulatory monitoring and an early epidural catheter system for patient-controlled epidural analgesia should be performed in the initial phase [46]. In the early dilation stage, attention must be paid to bladder and bowel management. A filled bladder can inhibit uterine contractility; the bladder should be emptied intermittently. The body position should be changed regularly and good positioning achieved using supportive aids. Special mattresses can avoid pressure injuries [6]. To facilitate breathing, the upper body should be positioned upright.

\section{Expulsion phase}

In the second stage of labor, the woman's active participation may be limited, and a vaginal operative delivery using vacuum or forceps may be indicated. Upright positions and changes in position can help to promote the birthing process. Dam injury and prophylactic episiotomy should be avoided if possible. The suture-healing process is prolonged in women with SCI. Studies show meaningful variances in section rates $[3,4,47]$ due to lack of birthing process, unstable maternal pelvic conditions, and unfamiliarity of healthcare providers with SCI [48]. SCI is not an indication for performing a cesarean section [6]. Most women can deliver vaginally regardless their level of injury.

\section{Wound healing}

After birthing, a woman should be released from the hospital as soon as possible. Daily midwife visits for childbed monitoring are advisable. Assistance at home may be necessary, especially after birth injuries. Owing to the lack of pain sensitivity, daily wound control is needed. If this is not guaranteed, hospitalization is indicated until wound healing is complete. Furthermore, any birth injury can trigger AD.

In case of a birth injury, the following should be considered:

1. Relief of pelvic floor through frequent changes in position

2. Transfer with a lifter or assistance at home

3. Gentle cooling of dam injury

4. Careful hygiene of dam injury, such as regular replacement of the template and rinsing of the vulva, especially after defecation

5. Avoiding constipation

\section{Postnatal care}

During the postpartum period, the midwife should offer support and advice depending on the national guidelines for postnatal care. In Germany, the midwife is paid for postnatal visits up to 12 weeks.

\section{Regression of the uterus}

The resolution of the uterus in women with SCI differs only slightly from that of women without SCI. Owing to the altered tones of the abdominal and pelvic floor muscles, the 
fundus uteri can be palpated deeper in women with SCI. Moreover, given the possible lack of pain symptoms, a copious amount of lochia is discharged. Therefore, it is important to pay attention to color changes and odors to reduce lochia.

\section{Breastfeeding}

No problems regarding breastfeeding are expected in women with lesions at or below $\mathrm{T}_{6}$ [14]. Sensitive complete lesions above $T_{5}$ have no sensory effect on the nipples, which can lead to insufficient milk production and shorter breastfeeding duration (3.3 months) compared with women with low-level injuries (6.5 months) [49].

\section{Final remark}

\section{Challenges and requirements for interdisciplinary care}

Maternity care for women with SCI is lacking in the structural and procedural processes of many high-income countries $[2,50]$. Different care philosophies in the fields of gynecology/obstetrics and rehabilitation medicine may lead to miscommunication, tension, or even antagonism over the continuum of care. These issues should be resolved to benefit women with SCI and facilitate labor and birthing experiences. If women and their partners are to feel confident about their birthing choices, then a collaborative climate of acknowledgement, respect, and coordination is preferable. A collaborative culture, preferably led by the treating gynecologist or care manager, should be created [8]. Effective collaboration includes dynamic interaction between organizational and personal characteristics and initiatives that foster trustworthy and mutually respectful relationships between health professionals. Women with SCI generally possess a high level of health literacy and should be involved in medical decision-making processes.

\section{Future research}

These recommendations are intended to improve equity to and quality of reproductive care for women with SCI. However, further research is needed regarding basic epidemiological indicators, cause-effect data, and information about obstetrical issues (i.e., preterm delivery, birth indicators) to inform policy and program development. Hopefully, further research in this area will lead to better scientific knowledge and inform the review of this guideline by the year 2023 [10].

\section{Title of the long version guideline}

Schwangerschaft, Geburt und Wochenbett bei Frauen mit Querschnittlähmung, Classification S2k, AWMF-RegisterNr.: 179-002, Published 30.9.2018, Valid until 29.09.2023.

Acknowledgements The authors thank Prof. Dr. med. Michael von Wolff, chief physician for endocrinology and reproductive medicine, university clinic, Bern $(\mathrm{CH})$, for his helpful advice on the paragraph reproductive techniques and fertility.

Author contributions SB was responsible for writing and revising the paper and MS, KF, UL, SK, and IK provided critical feedback on the paper. All authors were members of the guideline committee.

\section{Compliance with ethical standards}

Conflict of interest The authors declare that they have no conflict of interest.

Publisher's note Springer Nature remains neutral with regard to jurisdictional claims in published maps and institutional affiliations.

\section{References}

1. WHO/UNFPA. Promoting sexual and reproductive health for persons with disabilities. Geneva-Switzerland: WHO/UNFPA; 2009. p. 27.

2. Bertschy S, Geyh S, Pannek J, Meyer T. Perceived needs and experiences with healthcare services of women with spinal cord injury during pregnancy and childbirth—a qualitative content analysis of focus groups and individual interviews. BMC Health Serv Res. 2015;15:234.

3. Sterling L, Keunen J, Wigdor E, Sermer M, Maxwell C. Pregnancy outcomes in women with spinal cord lesions. J Obstet Gynaecol Can. 2013;35:39-43.

4. Ghidini A, Simonson M. Pregnancy after spinal cord injury: a review of the literature. Top Spinal Cord Inj Rehabil. 2011;16:93-103.

5. Bertschy S, Bostan C, Meyer T, Pannek J. Medical complications during pregnancy and childbirth in women with SCI in Switzerland. Spinal Cord. 2016;54:183-7.

6. Dawood R, Altanis E, Ribes-Pastor P, Ashworth F. Pregnancy and spinal cord injury. Obstet Gynaecol. 2014;16:1699-107. https:// doi.org/10.1111/tog.12083.

7. Bertschy S. Maternity care services for women with disabilities during pregnancy and childbirth in Switzerland: learning from the experiences of women with spinal cord injuries and their practitioners to optimise maternity care services. Dissertation. Lucerne: University of Lucerne; 2017.

8. Bertschy S, Pannek J, Meyer T. Decision making under uncertainty: Swiss providers' experiences in caring for women with spinal cord injury during pregnancy and childbirth-an expert interview study. BMC Pregnancy Childbirth. 2016;16:181. https:// doi.org/10.1186/s12884-016-0976-y.

9. Camune BD. Challenges in the management of the pregnant woman with spinal cord injury. J Perinat Neonatal Nurs. 2013;27:225-31.

10. DGGG \& DMGP, AWMF Guidelines "Schwangerschaft, Geburt und Wochenbett bei Frauen mit Querschnittlähmung", Regist No 179-002. 2018. https://www.awmf.org/leitlinien/detail/11/179002.html. Accessed 8 Sept 2019. 
11. Iezzoni LI, Yu J, Wint AJ, Smeltzer SC, Ecker JL. Prevalence of current pregnancy among US women with and without chronic physical disabilities. Med Care. 2013;51:555-62.

12. Iezzoni LI, Chen Y, McLain ABJ. Current pregnancy among women with spinal cord injury: findings from the US national spinal cord injury database. Spinal Cord. 2015;53:821-6.

13. Crane DA, Doody DR, Schiff MA, Mueller BA. Pregnancy outcomes in women with spinal cord injuries: a population-based study. PM R. 2019;11:795-806. https://doi.org/10.1002/pmrj.12122.

14. Morton C, Le JT, Shahbandar L, Hammond C, Murphy EA, Kirschner KL. Pregnancy outcomes of women with physical disabilities: a matched cohort study. PM R. 2013;5:90-8.

15. Pannek J, Bertschy S. Mission impossible? Urological management of patients with spinal cord injury during pregnancy: a systematic review. Spinal Cord. 2011;49:1028-32.

16. DMGP, AWMF Guidelines "Neurogene Darmfunktionsstörung bei Querschnittlähmung”, Regist No 179-004. 2019. https://www. awmf.org/leitlinien/detail/11/179-004.html Accessed 8 Sept 2019.

17. Consortium for Spinal Cord Medicine Clinical Practice Guidelines. Pressure ulcer prevention and treatment following spinal cord injury: a clinical practice guideline for health-care professionals. J Spinal Cord Med. 2001;24(Suppl 1):S40-101.

18. Geng V, Obereisenbuchner J, Senft B, Wirschinger S. Netzwerk Ernährung Querschnittgelähmter, Ernährungsempfehlung für Querschnittgelähmte 5-2014 Selbstverlag Manfred-Sauer-Stiftung. Lobbach. 2015. https://www.manfred-sauer-stiftung.de/fileadmin/ user_upload/mss/BZE-Downloads/B_ErnaehrungsempfehlungQS_ Netzwerk_1504.pdf.

19. Tollefsen E, Fondenes O. Respiratory complications associated with spinal cord injury. Tidsskr Nor Laegeforen. 2012;132:1111-4.

20. ACOG committee on obstetric practice opinion. Number 275. Obstetric management of patients with spinal cord injuries. Obstet Gynecol. 2002;100:625-7.

21. Krassioukov A, Warburton DE, Teasell R, Eng JJ. A systematic review of the management of autonomic dysreflexia after spinal cord injury. Arch Phys Med Rehabil. 2009;90:682-95.

22. Liu N, Fougere R, Zhou MW, Nigro MK, Krassioukov AV. Autonomic dysreflexia severity during urodynamics and cystoscopy in individuals with spinal cord injury. Spinal Cord. 2013;51: 863-7.

23. Liu N, Zhou M, Biering-Sorensen F, Krassioukov AV. Iatrogenic urological triggers of autonomic dysreflexia: a systematic review. Spinal Cord. 2015;53:500-9.

24. Jacobsen AF, Skjeldestad FE, Sandset PM. Incidence and risk patterns of venous thromboembolism in pregnancy and puerperium-a register-based case-control study. Am J Obstet Gynecol. 2008;198:233 e1-7.

25. Committee on Practice Bulletins-Gynecology, American College of Obstetricians and Gynecologists. ACOG Practice Bulletin No. 84: Prevention of deep vein thrombosis and pulmonary embolism. Obstet Gynecol. 2007;110(2 Pt 1):429-40.

26. Iezzoni LI, Wint AJ, Smeltzer SC, Ecker JL. Recommendations about pregnancy from women with mobility disability to their peers. Womens Health Issues. 2017;27:75-82.

27. DGU, AWMF Guidelines "Epidemiologie, Diagnostik, Therapie, Prävention und Management unkomplizierter, bakterieller, ambulant erworbener Harnwegsinfektionen bei erwachsenen Patienten", Regist No 043-044. https://www.awmf.org/leitlinien/ detail/11/043-044.html. Accessed 8 Sept 2019.

28. Charieté-Universitätsmedizin. Pharmakovigilanz- und Beratungszentrum für Embryonaltoxikologie. Berlin: Charieté-Universitätsmedizin, Campus Virchow-Klinikum; 2019.

29. Richardson JL, Stephens S, Yates LM, Diav-Citrin O, Arnon J, Beghin D, et al. Pregnancy outcomes after maternal varenicline use; analysis of surveillance data collected by the European
Network of Teratology Information Services. Reprod Toxicol. 2017;67:26-34. Epub 2016/11/17.

30. Nitti VW, Dmochowski R, Herschorn S, Sand P, Thompson C, Nardo C, et al. OnabotulinumtoxinA for the treatment of patients with overactive bladder and urinary incontinence: results of a phase 3, randomized, placebo controlled trial. J Urol. 2013;189: 2186-93.

31. Yuan H, Cui Y, Wu J, Peng P, Sun X, Gao Z. Efficacy and adverse events associated with use of onabotulinumtoxinA for treatment of neurogenic detrusor overactivity: a meta-analysis. Int Neurourol J. 2017;21:53-61.

32. Dietz V, Schöls L. Syndrom der spastischen Parese und spastische Spinalparalysen. In: Brandt T, Diener HC, Gerolff C, editor. Therapie und Verlauf neurologischer Erkrankungen. Stuttgart: Kohlhammer; 2012;1139-48.

33. DGN, AWMF Guidelines "Therapie des spatischen Syndroms". Regist No 030-078. https://www.awmf.org/leitlinien/detail/11/030078.html. Accessed 8 Sept 2019.

34. Cullen L, Titler MG. Promoting evidence-based practice: an internship for staff nurses. Worldviews Evid Based Nurs. 2004;1:215-23.

35. Winterfeld U, Merlob P, Baud D, Rousson V, Panchaud A, Rothuizen LE, et al. Pregnancy outcome following maternal exposure to pregabalin may call for concern. Neurology 2016;86: 2251-7.

36. Schäfers M, Schmidt M. Schmerztherapie bei Schwangeren und Stillenden. In: Maier C, Diener H-C, Bingel U, editors. Schmerzmedizin, Interdisziplinäre Diagnose- und Behandlungsstrategien. München, Germany: Elsevier GmbH; 2016. p. 361-70.

37. (DGGG) DGfGuGeV. Hypertensive Schwangerschaftserkrankungen: diagnostik und therapie. 2019. https://www.awmf.org/ leitlinien/detail/anmeldung/1/11/015-018.html.

38. Khunda A, Karmarkar R, Abtahi B, Gonzales G, Elneil S. Pregnancy in women with Fowler's syndrome treated with sacral neuromodulation. Int Urogynecol J. 2013;24:1201-4.

39. Wollner J, Krebs J, Pannek J. Sacral neuromodulation in patients with neurogenic lower urinary tract dysfunction. Spinal Cord. 2016;54:137-40. https://doi.org/10.1038/sc.2015.124.

40. Rasmussen MM, Kutzenberger J, Krogh K, Zepke F, Bodin C, Domurath B, et al. Sacral anterior root stimulation improves bowel function in subjects with spinal cord injury. Spinal Cord. 2015;53:297-301.

41. Bughi S, Shaw SJ, Mahmood G, Atkins RH, Szlachcic Y. Amenorrhea, pregnancy, and pregnancy outcomes in women following spinal cord injury: a retrospective cross-sectional study. Endocr Pract 2008;14:437-41.

42. Burns R, Clark VA. Epidural anaesthesia for caesarean section in a patient with quadriplegia and autonomic hyperreflexia. Int $\mathrm{J}$ Obstet Anesth. 2004;13:120-3.

43. Murphy CJ, Stanley E, Kavanagh E, Lenane PE, McCaul CL. Spinal dysraphisms in the parturient: implications for perioperative anaesthetic care and labour analgesia. Int J Obstet Anesth. 2015;24:252-63.

44. McLain ABJ, Massengill BA, Klebine MA. Pregnancy in women with spinal cord injury. Model Systems Knowledge Translation Center; 2015. https://msktc.org/lib/docs/Factsheets/SCI_and_Pregna ncy_.pdf. Accessed 23 Oct 2019.

45. Kuczkowski KM. Labor analgesia for the parturient with spinal cord injury: what does an obstetrician need to know? Arch Gynecol Obstet. 2006;274:108-12.

46. Sharpe EE, Arendt KW, Jacob AK, Pasternak JJ. Anesthetic management of parturients with pre-existing paraplegia or tetraplegia: a case series. Int J Obstet Anesth. 2015;24: $77-84$. 
47. Le Liepvre H, Dinh A, Idiard-Chamois B, Chartier-Kastler E, Phe $\mathrm{V}$, Even A, et al. Pregnancy in spinal cord-injured women, a cohort study of 37 pregnancies in 25 women. Spinal Cord. 2017;55:167-171. https://doi.org/10.1038/sc.2016.138.

48. Signore C, Spong CY, Krotoski D, Shinowara NL, Blackwell SC. Pregnancy in women with physical disabilities. Obstet Gynecol. 2011;117:935-47.
49. Holmgren T, Lee AHX, Hocaloski S, Hamilton LJ, Hellsing I, Elliott $\mathrm{S}$, et al. The influence of spinal cord injury on breastfeeding ability and behavior. J Hum Lact. 2018;34:556-65.

50. Tarasoff LA. "We don't know. We've never had anybody like you before": barriers to perinatal care for women with physical disabilities. Disabil Health J. 2017;10:426-33. 